\title{
Rocuronium and sugammadex under TOF monitoring on mECT
}

\author{
Shinsuke Hamaguchi ${ }^{1} \cdot$ Nobuko Tezuka $^{1} \cdot$ Masaru Nagao $^{1}$
}

Received: 4 July 2014 / Accepted: 24 March 2015 / Published online: 7 April 2015

(C) Japanese Society of Anesthesiologists 2015

Keywords Rocuronium $\cdot$ Sugammadex $\cdot \mathrm{TOF} \cdot \mathrm{mECT}$

To the Editor:

A 48-year-old female, who had schizophrenia with rectourinary disturbance due to thoracic vertebular fracture and $5 \mathrm{mg}$ a day of distigmine bromide was administered, was scheduled modified electroconvulsive therapy (mECT). On first and second mECT, apnea continued within $60 \mathrm{~min}$ until spontaneous breathing occurred after convulsion using $0.5-1 \mathrm{mg} / \mathrm{kg}$ of suxamethonium and $2 \mathrm{mg} / \mathrm{kg}$ of thiopental. We considered that the pharmacological effect of suxamethonium has been prolonged due to cholinesterase inhibition by distigmine bromide from previous report $[1,2]$.

Therefore, on the third to sixth mECT, we administered rocuronium $0.6 \mathrm{mg} / \mathrm{kg}$ after thiopental $2 \mathrm{mg} / \mathrm{kg}$ administration under the train of four ratios (TOFR) monitoring with TOF-Watch ${ }^{\mathrm{TM}}$ SX (MIPM GmbH, Germany). After convulsion of mECT, $0 \%$ of TOFR is considered. Then we administered $4 \mathrm{mg} / \mathrm{kg}$ of sugammadex and the value of TOFR reached $100 \%$ [3]. After 2 min of administration of sugammadex, her spontaneous breathing appeared immediately.

There are no reports regarding successful management using rocuronium and sugammadex under monitoring TOFR to avoid prolonged apnea by suxamethonium on a patient that has undergone mECT using distigmine bromide.

Conflict of interest None.

\section{References}

1. Isono S, Iizuka K, Fukami G, Shinozuka N, Iyo M, Nishino T. Ubretid (distigmine bromide) taken to treat urinary retention prolongs the effect of suxamethonium. J Anesth. 2008;22:337.

2. Valdrighi JB, Fleming NW, Smith BK, Baker GL, White DA. Effects of cholinesterase inhibitors on the neuromuscular blocking action of suxamethonium. Br J Anaesth. 1994;72:237-9.

3. Hoshi H, Kadoi Y, Kamiyama J, Nishida A, Saito H, Taguchi M, Saito $\mathrm{S}$. Use of rocuronium-sugammadex, an alternative to succinylcholine, as a muscle relaxant during electroconvulsive therapy. J Anesth. 2011;25:286-90.

Shinsuke Hamaguchi

s-hama@dokkyomed.ac.jp

1 Department of Anesthesia and Pain Medicine, Dokkyo

University School of Medicine, 880 Kitakobayashi, Mibu,

Tochigi 321-0293, Japan 